\title{
An optimized non-linear vegetation index for estimating leaf area index in winter wheat
}

\author{
Wei Feng ${ }^{1}$ (D) Yapeng $\mathrm{Wu}^{1} \cdot \mathrm{Li} \mathrm{He}^{1} \cdot \mathrm{Xing} \mathrm{xu} \mathrm{Ren}^{1} \cdot$ Yangyang Wang ${ }^{1} \cdot \mathrm{Gege} \mathrm{Hou}^{1}$. \\ Yonghua Wang ${ }^{1} \cdot$ Wandai Liu ${ }^{1} \cdot$ Tiancai Guo ${ }^{1}$
}

Published online: 16 March 2019

(C) The Author(s) 2019

\begin{abstract}
Using hyperspectral remote sensing technology to monitor leaf area index (LAI) in a timely, fast and non-destructive manner is essential for accurate quantitative crop management. The relationships between existing vegetation indices (VIs) and LAI usually tend to saturate under dense canopies in crop production. The purpose of this study was to propose a new VI in which the estimating saturation is greatly weakened, and prediction accuracy is improved under conditions of high LAI in winter wheat (Triticum aestivum L.). The quantitative relationship between ground-based canopy spectral reflectance and LAI in wheat was investigated. The results showed that the optimized band combination, namely, the form of non-linear vegetation index (NLI) was more sensitive to changes in LAI. When $\lambda(\mathrm{x} 1)=798 \mathrm{~nm}$ and $\lambda(\mathrm{y} 2)=728 \mathrm{~nm}$, the band combination NLI $(798,728)$ had the highest $R^{2}$ of 0.757 . Among the common VIs, the modified triangular vegetation index 2 (MTVI2), the ratio spectral index [RSI (760,730)] and the 2-band enhanced vegetation index (EVI2) gave superior performance $\left(R^{2}>0.710\right)$ in terms of LAI estimation, but were worse than NLI $(798,728)$. Inspired by the modified non-linear vegetation index (MNLI), NLI $(798,728)$ was further optimized to become a novel optimized non-linear vegetation index (ONLI), which can be calculated by the formula $(1+0.05) \times\left(0.6 \times R_{798}^{2}-R_{728}\right) /\left(0.6 \times R_{798}^{2}+R_{728}+0.05\right)$. The unified ONLI model gave an $R^{2}$ of 0.779 and root mean square error (RMSE) of 1.013 across all datasets. These results indicate that the novel ONLI has strong adaptability to various cultivation conditions and can provide a good estimate of LAI in winter wheat.
\end{abstract}

Keywords Winter wheat $\cdot$ Leaf area index $\cdot$ Hyperspectral remote sensing $\cdot$ Non-linear vegetation index $\cdot$ Estimation model

Wei Feng

fengwei78@126.com

$\mathrm{Li} \mathrm{He}$

he-li19870308@163.com

1 National Engineering Research Centre for Wheat, State Key Laboratory of Wheat and Maize

Crop Science, Henan Agricultural University, \#15 Longzihu College District, Zhengzhou 450046, Henan, People's Republic of China 


\section{Introduction}

The leaf area index (LAI) is defined as the ratio of the one-sided surface area of all green leaves to the surface area per unit of land (Bréda 2003). LAI is a significant structural parameter for evaluating material and energy exchange such as photosynthesis, respiration and carbon and nutrient cycles in terrestrial ecosystems (Viña et al. 2011). LAI is often used to understand the physiological processes that occur in forest and crop canopies, and to forecast their growth and productivity (Haboudane et al. 2004). Therefore, the acquisition of LAI is particularly important.

There are many methods for obtaining LAI, and these are mainly divided into two categories: (1) traditional direct measurement and (2) indirect measurement. Traditional direct measurement includes methods such as the grid method, the coefficient method and the specific leaf weight method, among others (Daughtry 1990). The direct measurement method has relatively high precision; however, it is not suitable for large area measurement because of its destructiveness and high labor requirements (Chason et al. 1991), but it is often used to collect verification data for the development and improvement of indirect measurement methods (Cutini et al. 1998). The indirect measurement methods include the inclined point quadrat, the remote sensing method and optical methods using the LAI-2000 canopy analyser or other instruments (Wilson 1960; Arias et al. 2007; Casas et al. 2014). It is convenient and quick to obtain the LAI of vegetation by an indirect method, but such measurements are affected by cultivation factors and atmospheric conditions and still need to be corrected by the results obtained from a direct method (Chason et al. 1991). Remote sensing can rapidly monitor crop growth on a large scale and without damage, and a large number of studies have been undertaken (Hansen and Schjoerring 2003; He et al. 2016). Hence, the retrieval of LAI from remote sensing data is a popular and promising way to manage crops.

At present, in order to improve the ability to predict LAI, several vegetation indices (VIs) have been established by combining the bands that show good relationships with LAI in canopy spectral reflectance. The normalized difference vegetation index (NDVI) established by Rouse et al. (1974), is the most well known and widely used, and it is suitable for estimating LAI for various vegetation types (Heiskanen et al. 2012; Tillack et al. 2014). However, the relationship between LAI and NDVI tends to saturate in relatively dense canopies, and it shows a non-linear relationship as a whole (Baret and Guyot 1991; Gitelson 2004). In order to address this limitation, the development of different VIs usually comes from a modification of NDVI through wavelength optimization or the addition of a coefficient (Huete 1988; Huete et al. 2002; Gitelson 2004; Inoue et al. 2008). The green NDVI and normalized difference red edge (NDRE) improved the relationships with LAI by replacing the red band with other bands, but the prediction accuracy is still low (Gitelson and Merzlyak 1997; Fitzgerald et al. 2006).

Considering that canopy reflectance is easily affected by the optical properties of the soil, the second category of modified NDVI attempts to minimize the influence of soil background by adding a soil-adjusted factor (Huete 1988; Rondeaux et al. 1996). The representative indices are the soil-adjusted vegetation index (SAVI; Huete 1988), the optimized soil-adjusted vegetation index (OSAVI; Rondeaux et al. 1996) and the modified soil-adjusted vegetation index (MSAVI; Qi et al. 1994). These indices have been very successful at improving the LAI-reflectance relationship in circumstances where soil properties factor into the remote sensing scene (Liang et al. 2015). In addition, considering the significant reflectance contrast between the near-infrared (NIR) and red bands under dense 
canopies with high LAI, the wide dynamic range vegetation index (WDRVI) reduced the reflectance contrast by adding a weighting coefficient based on the NDVI, which improved the accuracy of the LAI estimation (Gitelson 2004; Cao et al. 2017).

Many studies have been carried out to address the relationship between VIs and LAI. The MERIS terrestrial chlorophyll index (MTCI; Dash and Curran 2004), the green chlorophyll index $\left(\mathrm{CI}_{\text {green }}\right.$; Gitelson et al. 2005) and the red-edge chlorophyll index $\left(\mathrm{CI}_{\text {red-edge }}\right.$; Gitelson et al. 2005) show a strong and significant linear relationship with LAI and are more sensitive to LAI than the widely used NDVI-like indices due to the linear relationship between canopy chlorophyll content and LAI (Viña et al. 2011; Tanaka et al. 2015). Moreover, in order to minimize the effect of leaf chlorophyll content on the prediction of LAI, Haboudane et al. (2004) designed the modified triangular vegetation indexes (MTVI1 and MTVI2) and the modified chlorophyll absorption ratio indices (MCARI1 and MCARI2) by enhancing the information from the near infrared band sensitive to leaf and canopy structure and weakening the influence of soil background. MTVI2 has been repeatedly shown to be sensitive to changes in LAI and can accurately estimate LAI (Haboudane et al. 2004; Liang et al. 2015; Tanaka et al. 2015). These VIs have improved abilities to estimate LAI, but the problem of saturation in the case of high LAI remains, which limits their application somewhat in actual production. Hence, developing new VIs that can weaken the estimation of saturation LAI still need to be continually explored using different approaches.

Wheat is one of the three most important grain crops in the world. The province of Henan is one of the major areas for wheat production in China, and it has made great contributions to national food security. However, in areas where wheat is grown in large dense populations, the LAI can often be $>8$ during active growth stages. There tends to be saturation in estimating LAI using conventional VIs from remote sensing data, which seriously limits the application of remote sensing technology in accurate management of crops. The objectives of this study were (1) to construct a novel VI to accurately estimate LAI by reducing the saturation effect, (2) to compare the capabilities of several established VIs with new indices for estimating LAI in wheat under different field test conditions and (3) to confirm a unified model of estimating LAI across different field conditions. The expected results would provide a method of LAI estimation by weakening the saturation and ensuring prediction accuracy under conditions of high vegetation coverage.

\section{Materials and methods}

\section{Experimental design}

In this study, the experiments were set up across three growing seasons at three locations in Henan Province, China. A total of five experiments that included different years, locations, nitrogen $(\mathrm{N})$ fertilizer rates, irrigation frequencies, planting density and cultivars of hexaploid winter wheat (Triticum aestivum L.) were investigated (Table 1). In addition, the nutrient contents and physical properties of the soil and the wheat sampling periods are also shown in Table 1 . Experiments 1 and 2 were conducted at the test station of Henan Agricultural University in Zhengzhou city $\left(34^{\circ} 51^{\prime} \mathrm{N}, 113^{\circ} 35^{\prime} \mathrm{E}\right)$ in fluvo-aquic soil. Experiments 3 and 5 were conducted on a private farm in Shangshui county, Zhoukou city $\left(33^{\circ} 33^{\prime} \mathrm{N}, 114^{\circ} 37^{\prime} \mathrm{E}\right)$ in lime concretion black soil. Experiment 4 was conducted at the test station of Henan Agricultural University situated in Yuanyang county, Xinxiang city $\left(35^{\circ} 6^{\prime} \mathrm{N}, 113^{\circ} 56^{\prime} \mathrm{E}\right)$ in fluvo-aquic soil. Experiments $1-3$ used a randomized block design, 


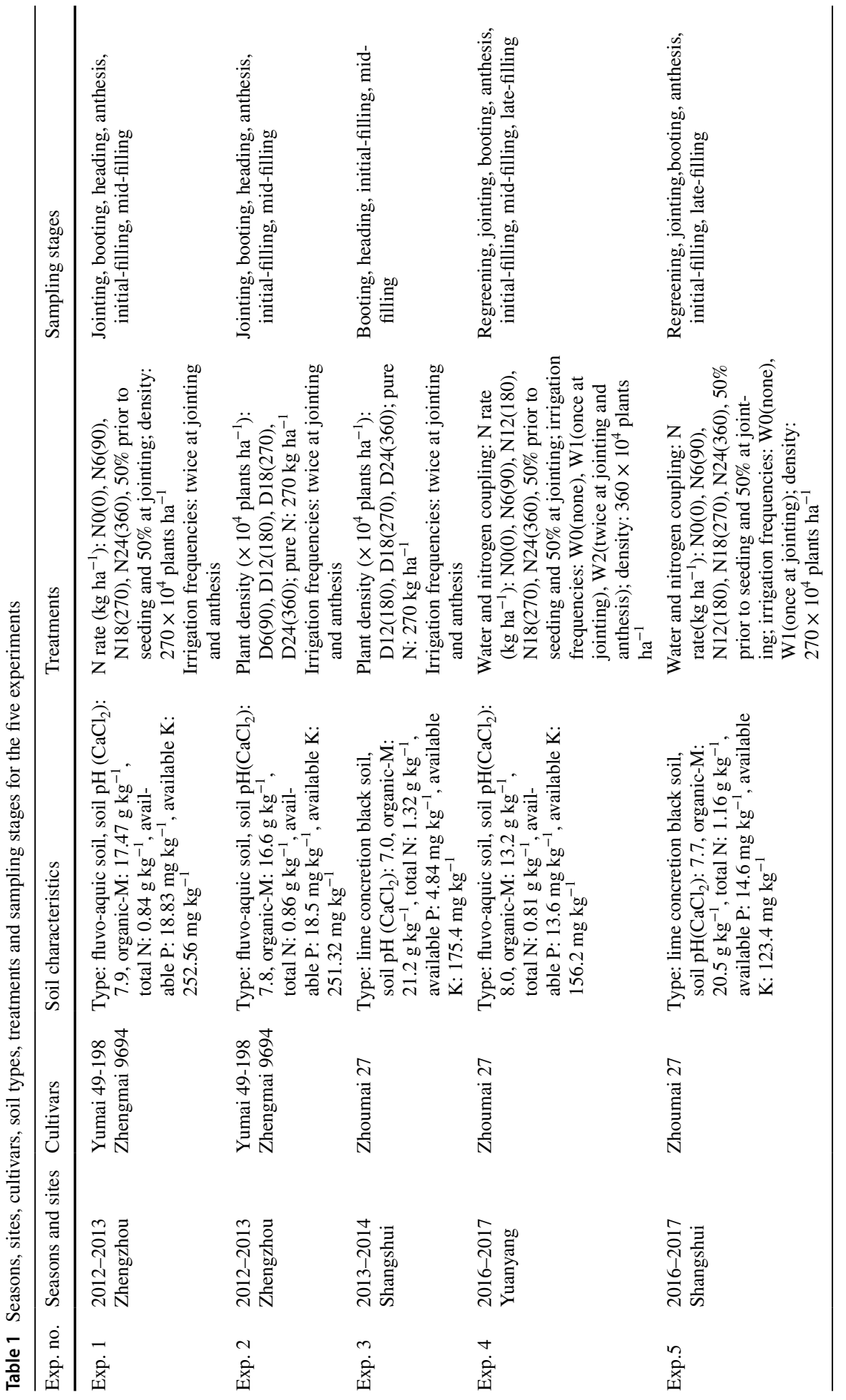


while experiments 4 and 5 were arranged in a split block design where the main zones were irrigation regimes and the secondary zones were nitrogen rates. All treatments were designed for three repetitions. Other management practices followed the local standard practices for winter wheat production.

\section{Measurement of canopy spectral reflectance}

The canopy spectral reflectance in all experiments was measured at a vertical angle from a height of approximately $1 \mathrm{~m}$ above the wheat canopy between 10:00 and 14:00 h (Beijing time) using an ASD FieldSpec Handheld spectrometer (HandHeld 2/1817, Analytical Spectral Devices Inc., Boulder, CO, USA) under clear-sky conditions. The spectrometer sensor is equipped with $25^{\circ}$ field of view optical fibers with a resolution of $3.5 \mathrm{~nm}$ and a sampling interval of $1.6 \mathrm{~nm}$. The working range of the spectrometer is from $325 \mathrm{~nm}$ to $1075 \mathrm{~nm}$. Moreover, the black and baseline reflectance was calculated using a $0.40 \times 0.40 \mathrm{~m}^{2}$ white calibration panel made of $\mathrm{BaSO}_{4}$. In order to obtain more representative canopy reflectance, spectral measurements were conducted at three sites in each plot and five spectra were collected at each site, and these fifteen spectra were averaged as a spectral sample of the entire plot.

\section{Measurement of LAI}

In order to match with the canopy spectral reflectance measurement, wheat plants with an area of $0.2 \mathrm{~m}^{2}(0.5 \mathrm{~m}$ long in two rows, with a spacing interval of $0.20 \mathrm{~m})$ were collected from each of the same three sites in the experimental plot and merged together as a sample of this plot. In the laboratory, 15 plants were randomly selected from each sample and all the fully expanded green leaves were separated to measure leaf area (LA) using the grid method. All leaves from each of the 15 plants were placed on a piece of square paper with $1 \times 1 \mathrm{~mm}^{2}$ grids, and their outlines were drawn with a pencil. The total number of $1 \mathrm{~mm}^{2}$ squares that the leaves covered were counted to calculate the LA. It is important to note that squares in which the leaf margin covered less than half were not counted, and those where the margin covered more than half were counted to calculate LA. There is a strong correlation between the area of fresh leaves and their dry weight (Champagne et al. 2003). The leaves were placed in an oven at $105{ }^{\circ} \mathrm{C}$ for $30 \mathrm{~min}$ to deactivate enzymes, and then baked to constant weight at $80{ }^{\circ} \mathrm{C}$. Finally, the dry weights (DW) of the leaves from 15 plants were obtained, and the remaining leaves were weighed. The LAI of a plot can be calculated by using the following formula:

$$
\mathrm{LAI}=\frac{\left(\mathrm{LA} \times \frac{\mathrm{DW}_{1}+\mathrm{DW}_{2}}{\mathrm{DW}_{1}}\right)}{S}
$$

where $\mathrm{DW}_{1}$ and $\mathrm{DW}_{2}$ are the dry weights of leaves from 15 plants and the remaining leaves, respectively, and $\mathrm{S}$ represents the sampling area per plot.

\section{Construction of a new spectral index}

There have been recent discoveries concerning the relationships between saturation of the NDVI, reflectance contrast and LAI (Gitelson 2004; Cao et al. 2017). The NDVI saturation is 
mainly caused by the reflectance contrast of the red and near-infrared (NIR) bands, while the contrast is caused by the dense canopy when LAI is high. Therefore, reducing the reflectance contrast under high LAI conditions is the key step to mitigate the saturation. Gitelson (2004) constructed the WDRVI to significantly reduce saturation by adding the weighting coefficient "a". Canopy reflectance is affected by many factors, and these influences interact with each other and are usually non-linear. The non-linear vegetation index (NLI) reduced the reflection contrast and saturation by using the squared values of the near infrared band reflectivity, which then linearized the relationship with LAI (Goel and Qin 1994).

Soil background conditions exert considerable influence on partial canopy spectra and the relationship between LAI and NDVI, and a soil adjustment factor has been proposed (Huete 1988). The optimal adjustment factor was found to be linearly correlated with LAI $(\mathrm{r}=-0.99)$ and it thereupon reduced soil-induced variations and improved the linearity between LAI and spectral indices, such as SAVI, OSAVI and MSAVI (Huete 1988; Qi et al. 1994; Rondeaux et al. 1996). Moreover, Gong et al. (2003) proposed the modified NLI (MNLI) by adding a soil factor to improve the prediction ability of LAI.

NDVI and NLI both belong to the two-band normalized difference (ND) indices, and these indices can be calculated from the following common expression:

$$
\mathrm{VI}_{\mathrm{C}}=\frac{R_{1}^{b_{1}}-R_{2}^{b_{2}}}{R_{1}^{b_{1}}+R_{2}^{b_{2}}}
$$

where for each $b_{1}$ and $b_{2} \in\{1,2\}, R_{1}$ and $R_{2}$ are the reflectance (\%) of the wavelength bands in the 400-900 $\mathrm{nm}$ region.

In addition, taking into account the advantages of WDRVI and MNLI on improving the inversion ability of growth indicators, the soil factor (L) and weighting coefficient (a) were introduced into the above formula, and optmized expression was as follows:

$$
\mathrm{VI}_{\mathrm{O}}=(1+\mathrm{L}) \times \frac{\mathrm{a} \times R_{1}^{b_{1}}-R_{2}^{b_{2}}}{\mathrm{a} \times R_{1}^{b_{1}}+R_{2}^{b_{2}}+\mathrm{L}}
$$

where "a" and "L" range from 0 to 1 in intervals of 0.05 .

\section{Data analysis}

Correlations between spectral indices and LAI were analyzed using MATLAB (MATLAB 9.0, MathWorks, Inc., Natick, MA, USA). The contour map of $R^{2}$ showing linear relationships between LAI and different combinations (a and L) based on $\mathrm{VI}_{\mathrm{O}}$ was plotted using SURFER (SURFER 10.0, Golden Software, Inc., Golden, CO, USA).

The general performance of the models was evaluated by comparing the differences in determination coefficient $\left(R^{2}\right)$ and root mean square error (RMSE). Higher $R^{2}$ values and lower RMSE indicate that a VI has better precision in estimating LAI. RMSE was calculated using the following Eq. (4):

$$
R M S E=\sqrt{\frac{1}{n} \times \sum_{i=1}^{n}\left(P_{i}-O_{i}\right)^{2}}
$$


where $P_{i}$ and $O_{i}$ are the predicted and the observed values, respectively, and $\mathrm{n}$ is the number of samples.

\section{Results}

\section{Dynamic changes in LAI}

Figure 1 shows that LAI is regulated by $\mathrm{N}$ rates, irrigation and planting density. LAI increases with increases in nitrogen fertilizer rates, irrigation frequency and planting density, and generally shows a trend of first rising, peaking at booting or heading and then decreasing as the growth stages progress. LAI reached its peak value at the booting stage under both different $\mathrm{N}$ rates (Fig. 1a) and irrigation frequencies (Fig. 1b) for cultivar 'Zhoumai 27', and the maximum value of LAI was >9.0. As shown in Fig. 1c and d, the stage at which the maximum LAI value was reached varied based on the planting density; for two types of cultivars, LAI reached the peak value at booting stage for lower densities (D6 and D12) and at heading stage for higher densities (D18 and D24). There was a difference in LAI between cultivars; the LAI of the horizontal cultivar 'Zhengmai 9694' was greater than that of the erect cultivar 'Yumai 49-198' during jointing and anthesis, and the LAI of 'Zhengmai 9694' was slightly lower than that of 'Yumai 49-198' after anthesis.

(a)
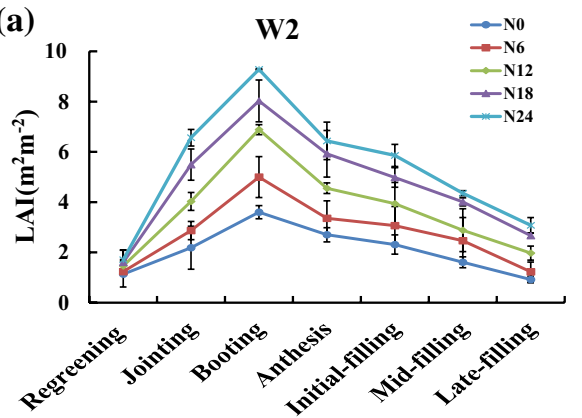

Growth stages

(c)

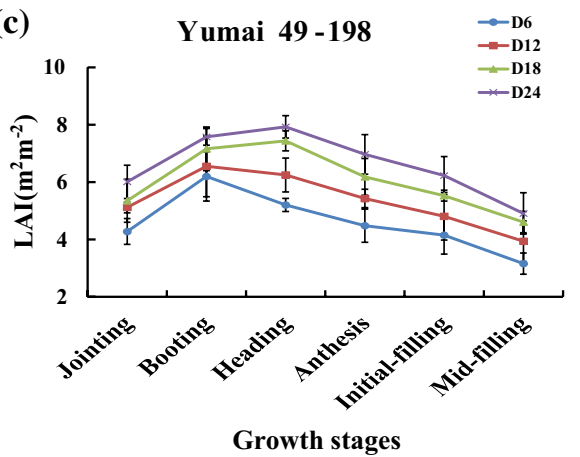

(b)

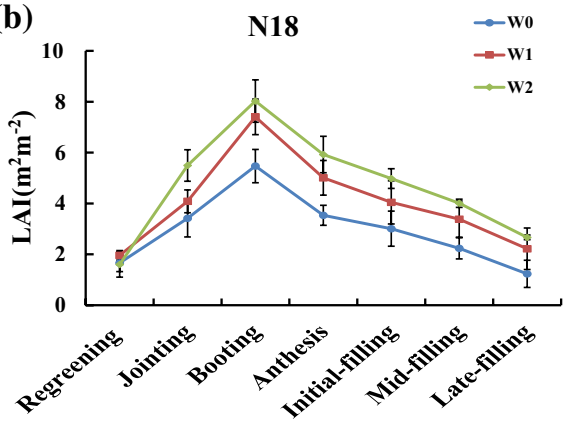

Growth stages

(d)

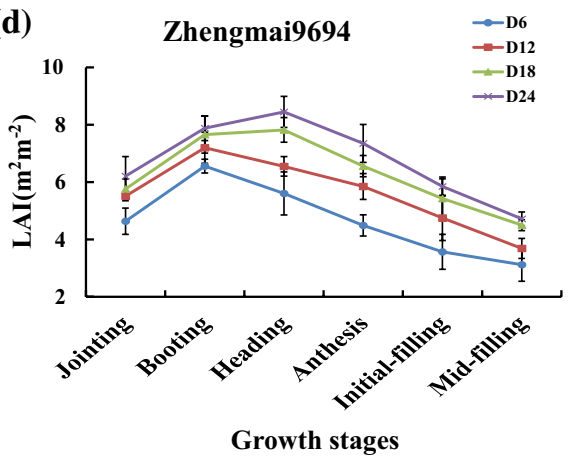

Fig. 1 Dynamic maps of LAI with respect to growth stages in winter wheat. Note $\mathbf{a}$ and $\mathbf{b}$ are data from experiment $4 ; \mathbf{c}$ and $\mathbf{d}$ are data from experiment 2 


\section{Comparisons of relationships between LAl and selected VIs}

Twenty commonly used VIs were selected to establish relationships with LAI using data from experiments 1-5 (Table 2). Fifteen out of the 20 selected VIs were two-band indices, in which the ratio spectral index [RSI $(760,730)]$ and the 2-band enhanced vegetation index (EVI2) had the highest $R^{2}(0.719$ and 0.717$)$, and the lowest RMSE (1.147 and 1.150) (Fig. 2). Except for the lower $R^{2}(0.495)$ of the modified normalized difference spectral index [mNDSI $(940,950,540)]$, the other four VIs involving $>3$ wavebands generated higher $R^{2}$ values, above 0.680 , and MTVI2 and the Vogelmann index 3 (VOG3) gave superior performances with $R^{2}$ of 0.734 and 0.715 , and RMSE of 1.114 and 1.155, respectively. Furthermore, compared with the same form VIs, those VIs comprised of the red edge band gave better performance in LAI estimation, such as NDRE $\left(R^{2}=0.669\right)$ and NDVI $(810,680)\left(R^{2}=0.554\right)$. Overall, MTVI2, RSI $(760,730)$ and EVI2 were superior to other indices in terms of LAI estimation, and the $R^{2}$ values were $>0.710$. The quantitative relationships between the three best performing indices [MTVI2, RSI $(760,730)$ and EVI2] and the widely used MTCI are depicted in Fig. 3,

Table 2 Summary of twenty selected spectral indices reported in the literature and three from this study

\begin{tabular}{|c|c|c|}
\hline Spectral index & Calculation formula & References \\
\hline SR705 & $\mathrm{R}_{750} / \mathrm{R}_{705}$ & Gitelson and Merzlyak (1994) \\
\hline $\operatorname{NDVI}(810,680)$ & $\left(\mathrm{R}_{810}-\mathrm{R}_{680}\right) /\left(\mathrm{R}_{810}+\mathrm{R}_{680}\right)$ & Rouse et al. (1974) \\
\hline Green NDVI & $\left(\mathrm{R}_{750}-\mathrm{R}_{550}\right) /\left(\mathrm{R}_{750}+\mathrm{R}_{550}\right)$ & Gitelson and Merzlyak (1997) \\
\hline NDRE & $\left(\mathrm{R}_{790}-\mathrm{R}_{720}\right) /\left(\mathrm{R}_{790}+\mathrm{R}_{720}\right)$ & Fitzgerald et al. (2006) \\
\hline WDRVI & $\left(0.12 \times \mathrm{R}_{810}-\mathrm{R}_{680}\right) /\left(0.12 \times \mathrm{R}_{810}+\mathrm{R}_{680}\right)$ & Gitelson (2004) \\
\hline OSAVI & $(1+0.16) \times\left(\mathrm{R}_{800}-\mathrm{R}_{670}\right) /\left(\mathrm{R}_{800}+\mathrm{R}_{670}+0.16\right)$ & Rondeaux et al. (1996) \\
\hline MTCI & $\left(\mathrm{R}_{754}-\mathrm{R}_{709}\right) /\left(\mathrm{R}_{709}-\mathrm{R}_{681}\right)$ & Dash and Curran (2004) \\
\hline $\mathrm{CI}_{\text {red-edge }}$ & $\mathrm{R}_{790} / \mathrm{R}_{720}-1$ & Gitelson et al. (2005) \\
\hline $\mathrm{CI}_{\text {green }}$ & $\left(\mathrm{R}_{840-870}\right) / \mathrm{R}_{550}-1$ & Gitelson et al. (2005) \\
\hline EVI2 & $2.5 \times\left(\mathrm{R}_{800}-\mathrm{R}_{660}\right) /\left(1+\mathrm{R}_{800}+2.4 \times \mathrm{R}_{660}\right)$ & Jiang et al. (2008) \\
\hline VOG3 & $\left(\mathrm{R}_{734}-\mathrm{R}_{747}\right) /\left(\mathrm{R}_{715}+\mathrm{R}_{720}\right)$ & Zarco-Tejada et al. (2001) \\
\hline RDVI & $\left(\mathrm{R}_{800}-\mathrm{R}_{670}\right) /\left(\mathrm{R}_{800}+\mathrm{R}_{670}\right)^{0.5}$ & Roujean and Breon (1995) \\
\hline $\mathrm{VI}_{\mathrm{opt}}$ & $(1+0.45) \times\left[\left(\mathrm{R}_{800}\right)^{2}+1\right] /\left(\mathrm{R}_{670}+0.45\right)$ & Reyniers et al. (2006) \\
\hline MTVI2 & $\begin{array}{l}1.5 \times\left[1.2 \times\left(\mathrm{R}_{800}-\mathrm{R}_{550}\right)-2.5 \times\left(\mathrm{R}_{670}-\mathrm{R}_{550}\right)\right] / \\
{\left[\left(2 \times \mathrm{R}_{800}+1\right)^{2}-6 \times \mathrm{R}_{800}+5 \times\left(\mathrm{R}_{670}\right)^{0.5}-0.5\right]^{0.5}}\end{array}$ & Haboudane et al. (2004) \\
\hline NLI & $\left(\mathrm{R}_{810}^{2}-\mathrm{R}_{680}\right) /\left(\mathrm{R}_{810}^{2}+\mathrm{R}_{680}\right)$ & Goel and Qin (1994) \\
\hline MNLI & $(1+0.5) \times\left(\mathrm{R}_{810}^{2}-\mathrm{R}_{680}\right) /\left(\mathrm{R}_{810}^{2}+\mathrm{R}_{680}+0.5\right)$ & Gong et al. (2003) \\
\hline NDSI $(940,730)$ & $\left(\mathrm{R}_{940}-\mathrm{R}_{730}\right) /\left(\mathrm{R}_{940}+\mathrm{R}_{730}\right)$ & Cao et al. (2017) \\
\hline mNDSI $(940,950,540)$ & $\left(\mathrm{R}_{940}-0.9 \times \mathrm{R}_{950}-\mathrm{R}_{540}\right) /\left(\mathrm{R}_{940}-0.9 \times \mathrm{R}_{950}+\mathrm{R}_{540}\right)$ & Cao et al. (2017) \\
\hline $\operatorname{RSI}(760,730)$ & $\mathrm{R}_{760} / \mathrm{R}_{730}$ & Tanaka et al. (2015) \\
\hline NDSI(760,730) & $\left(\mathrm{R}_{760}-\mathrm{R}_{730}\right) /\left(\mathrm{R}_{760}+\mathrm{R}_{730}\right)$ & Tanaka et al. (2015) \\
\hline $\operatorname{NLI}(810,560)$ & $\left(\mathrm{R}_{810}^{2}-\mathrm{R}_{560}\right) /\left(\mathrm{R}_{810}^{2}+\mathrm{R}_{560}\right)$ & This study \\
\hline $\operatorname{NLI}(798,728)$ & $\left(\mathrm{R}_{798}^{2}-\mathrm{R}_{728}\right) /\left(\mathrm{R}_{798}^{2}+\mathrm{R}_{728}\right)$ & This study \\
\hline ONLI & $\begin{array}{l}(1+0.05) \times\left(0.6 \times \mathrm{R}_{798}^{2}-\mathrm{R}_{728}\right) / \\
\left(0.6 \times \mathrm{R}_{798}^{2}+\mathrm{R}_{728}+0.05\right)\end{array}$ & This study \\
\hline
\end{tabular}

$\mathrm{R}_{750}, \mathrm{R}_{705}, \ldots$ and $\mathrm{R}_{728}$ are the spectral reflectance at $750,705, \ldots$ and $728 \mathrm{~nm}$ 
Fig. 2 Comparisons of $R^{2}$ and RMSE for the linear relationships between LAI and the twenty reported spectral indices using data from experiments 1-5 $(\mathrm{n}=819)$

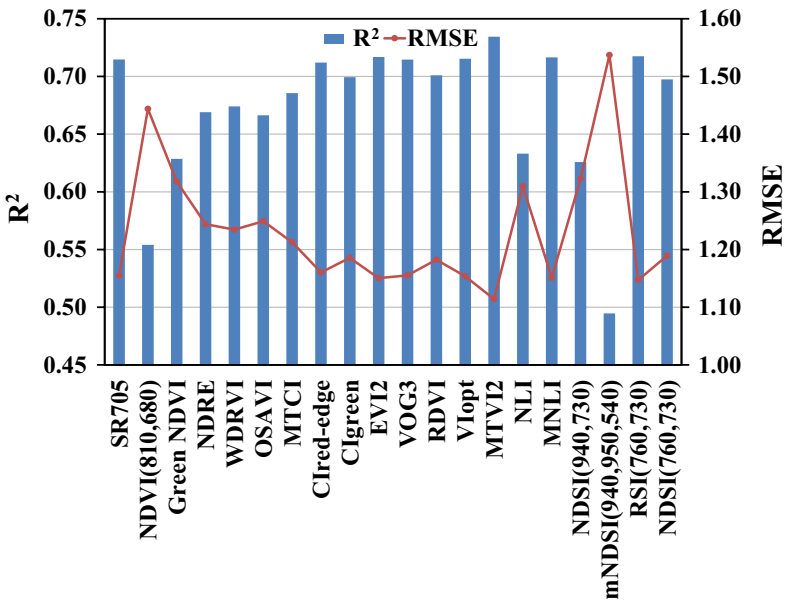

(a)

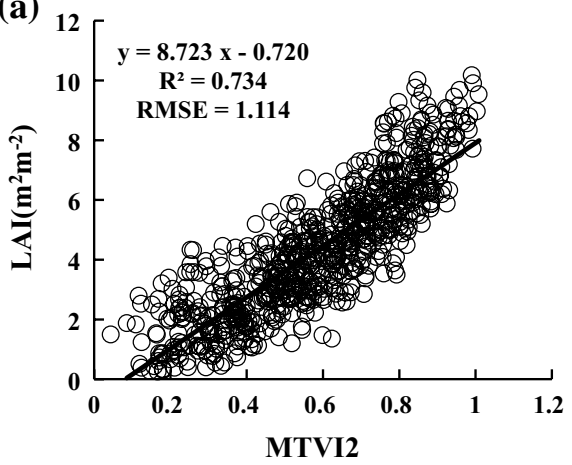

(b)

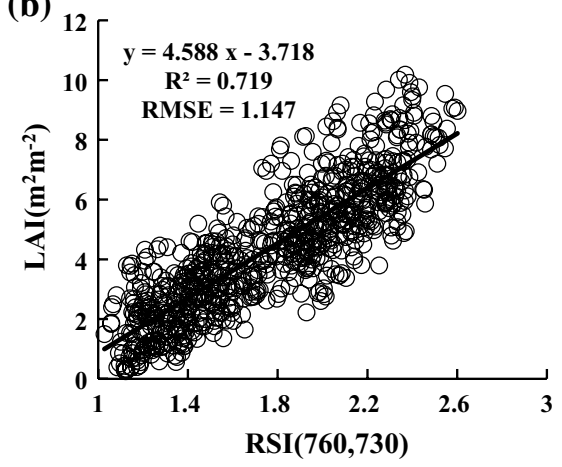

(c)

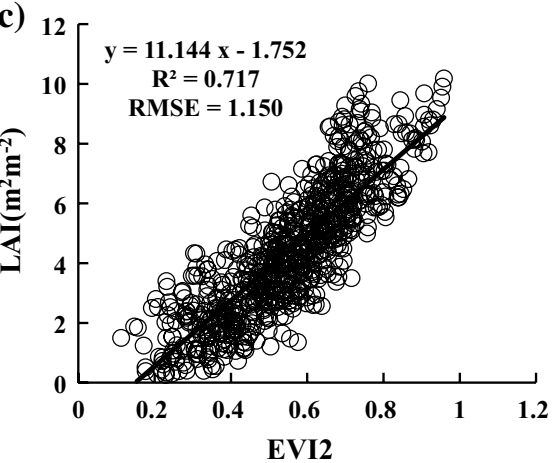

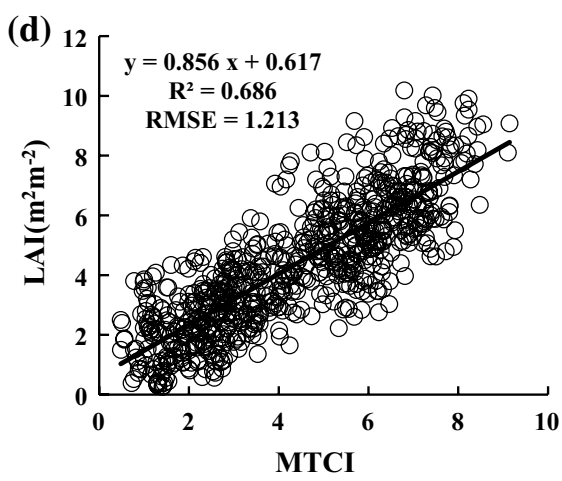

Fig. 3 Quantitative relationships of LAI with four common spectral indices; MTVI2 (a), RSI (760,730) (b), $\mathrm{EVI} 2$ (c) and MTCI (d) $(\mathrm{n}=819)$ 
and these VIs could reflect changes in the LAI to some extent. In addition, when LAI exceeded 7.5, the distribution of scattered points usually deviated from the fitted line.

\section{Correlation of LAI with ND-type parameters}

The contour maps of $R^{2}$ for the linear relationships between LAI and the ND ratios of all waveband combinations [four groups: $\lambda(\mathrm{x} 1)$ and $\lambda(\mathrm{y} 1), \lambda(\mathrm{x} 1)$ and $\lambda(\mathrm{y} 2), \lambda(\mathrm{x} 2)$ and $\lambda(\mathrm{y} 1)$, $\lambda(\mathrm{x} 2)$ and $\lambda(\mathrm{y} 2)]$ are shown in Fig. 4. The band combinations of two forms: $\lambda(\mathrm{x} 1)$ and $\lambda(\mathrm{y} 2), \lambda(\mathrm{x} 2)$ and $\lambda(\mathrm{y} 1)$ were more sensitive to changes in LAI. Because the two forms are essentially identical, the first one was chosen for analysis. The band combinations with $R^{2}>0.70$ were mainly distributed in two separate regions: (i) $[\lambda(\mathrm{x} 1): 740-900 \mathrm{~nm}, \lambda(\mathrm{y} 2)$ : $530-570 \mathrm{~nm}]$ and (ii) $[\lambda(\mathrm{x} 1): 740-900 \mathrm{~nm}, \lambda(\mathrm{y} 2): 700-750 \mathrm{~nm}]$. These combinations have the same form and structure with the common NLI in the form of $\left(R_{1}^{2}-R_{2}\right) /\left(R_{1}^{2}+R_{2}\right)$. In the first region (i), the optimal combination is NLI $(868,550)[\lambda(\mathrm{x} 1)=868 \mathrm{~nm}$, $\lambda(\mathrm{y} 2)=550 \mathrm{~nm}$ ] with $R^{2}=0.713$ (Fig. 5a). However, the regression model with NLI $(868,550)$ as an independent variable produced a saturation trend at higher LAIs $>4.0$ (Fig. 5a). In the second region (ii), when $\lambda(\mathrm{x} 1)=798 \mathrm{~nm}$ and $\lambda(\mathrm{y} 2)=728 \mathrm{~nm}$, the band combination NLI $(798,728)$ had the highest $R^{2}=0.757$ (Fig. 5b). NLI $(798,728)$ demonstrated better predictive capability, and the regression model describes the dynamic changes in LAI well. Compared with the best-performing published index (MTVI2), the $R^{2}$ value of NLI $(798,728)$ increased by $3.13 \%$, which indicates that this parameter is a potential indicator of LAI in wheat.

\section{Optimization of non-linear VI}

Compared with the common NLI, the authors' NLI $(798,728)$ improved the predictive accuracy of LAI (Figs. 2, 5b), however, when LAI is greater than 7, NLI $(798,728)$ tends

Fig. 4 Contour map of $R^{2}$ for linear relationships between LAI and the normalized difference ratios of all possible waveband combinations. Note The $\lambda(\mathrm{x} 1)$ and $\lambda(\mathrm{y} 1)$ axes take the square values of the band reflectivity, while the $\lambda(\mathrm{x} 2)$ and $\lambda(\mathrm{y} 2)$ axes take the band reflectivity values

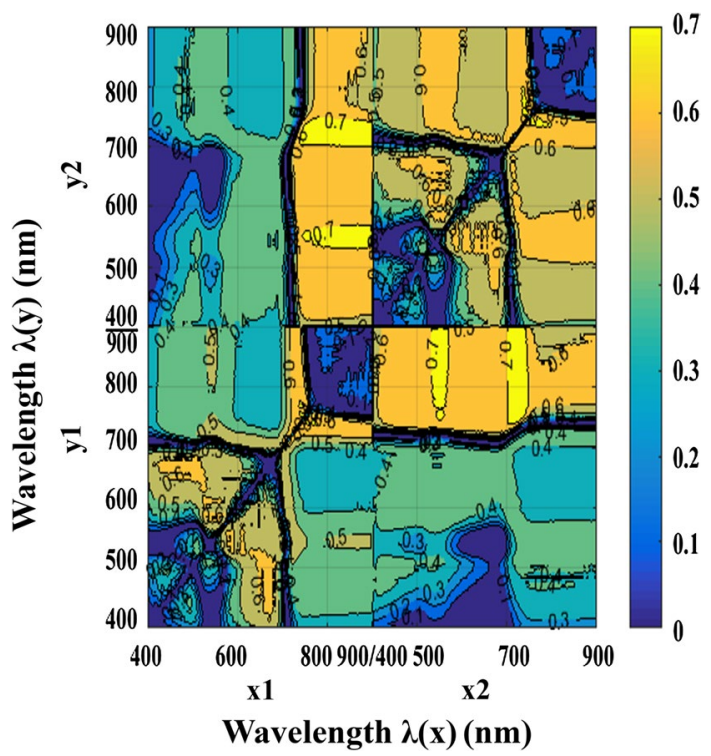



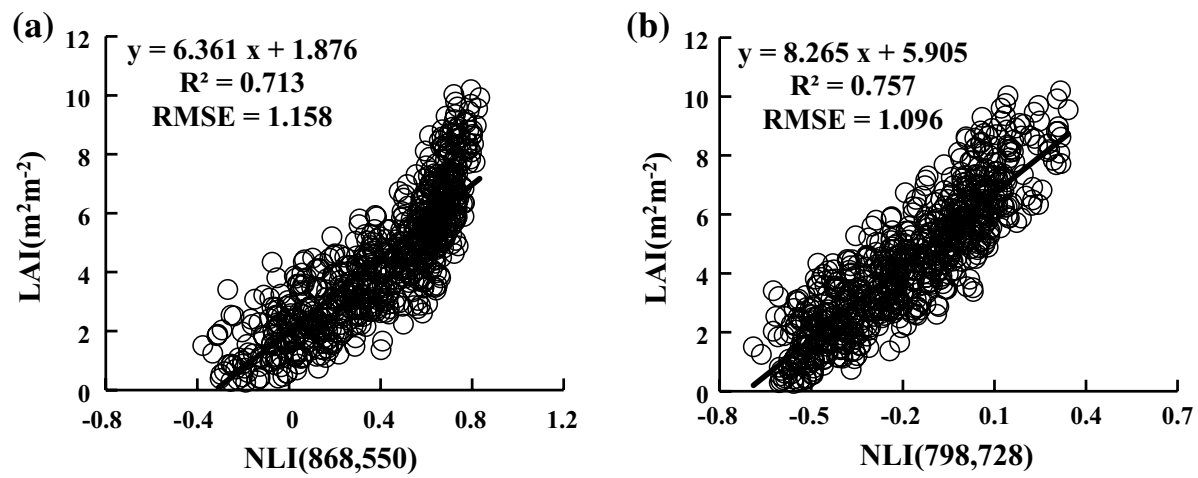

Fig. 5 Quantitative relationships of LAI with the optimized two-band combinations NLI (868,550) (a) and NLI $(798,728)(\mathbf{b})(\mathrm{n}=819)$

to be saturated to some extent and the data points are relatively scattered (RMSE $=1.096$, Fig. 5b). Thus further strengthen the relationship between NLI $(798,728)$ and LAI, a soil factor and a weighting coefficient were simultaneously introduced into NLI $(798,728)$. The contour map of $R^{2}$ for linear relationships between LAI and derivatives from NLI $(798,728)$ is shown in Fig. 6, and the higher $R^{2}$ (above 0.7 ) region occupied approximately half the area of the graph. When the "a" value is constant, the $R^{2}$ values decrease with increases in the "L" value, while the $R^{2}$ values increase with increases in the "a" value when the " $\mathrm{L}$ " remains constant. When $0<\mathrm{L}<0.3$ and $0.3<\mathrm{a}<1$, the region of the graph in which $R^{2}$

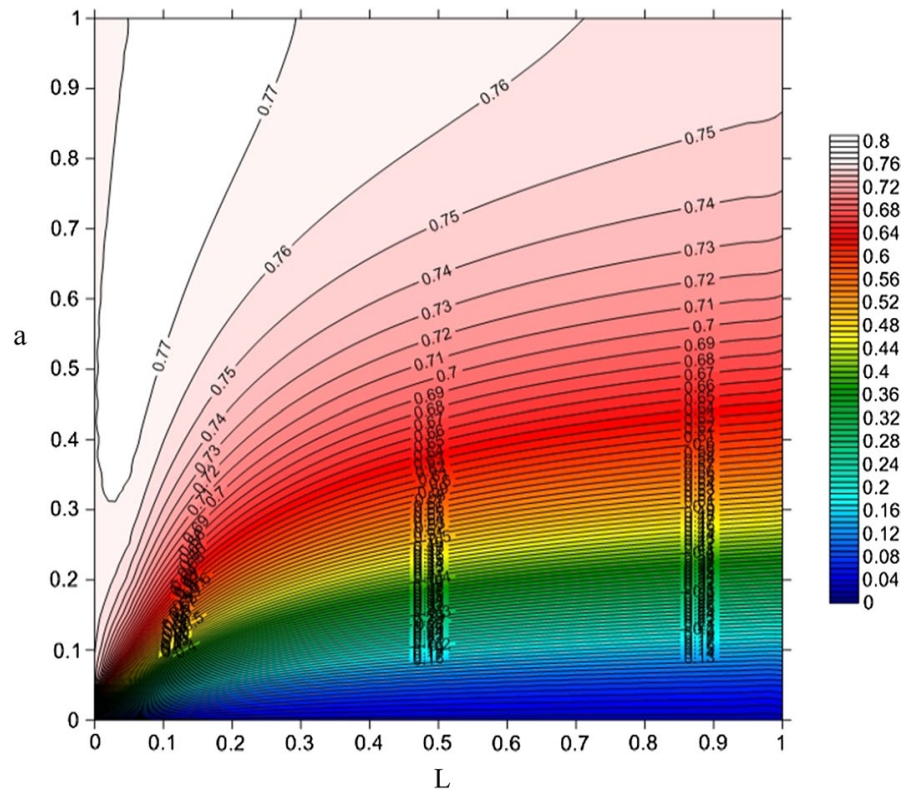

Fig. 6 Contour map of $R^{2}$ values for the linear relationships between LAI and the two factor combinations (a and L) based on NLI $(798,728)$ 
is $>0.77$ shows an approximately $\mathrm{V}$-shaped distribution; in particular, the combination of a $=0.6$ and $\mathrm{L}=0.05$ had the highest $R^{2}$ value (0.779), and this optimized NLI took the form of $(1+0.05) \times\left(0.6 \times R_{798}^{2}-R_{728}\right) /\left(0.6 \times R_{798}^{2}+R_{728}+0.05\right)$ and was called ONLI. The unified relationship between ONLI and LAI in winter wheat is plotted in Fig. 7; the improved $R^{2}$ and RMSE were 0.779 and 1.013 , respectively, and this index greatly weakened the saturation when estimating LAI.

\section{Effects of experimental conditions on the correlation between LAI and selected VIs}

The prediction accuracy of different VIs is highly dependent on the dataset used, therefore, the wheat data for a set of experimental variables that included location, cultivar, irrigation level, $\mathrm{N}$ rate, planting density and year were collected. The $R^{2}$ and RMSE of the linear relationships between seven VIs and the LAI for the different variabls are shown in Table 3. Compared with the six common VIs, the novel index ONLI had the highest prediction accuracy for nineteen out of the 21 experimental groups. In addition, the $R^{2}$ values of all VIs in the N0 treatment were $<0.50$, but this could not be taken into account because there is rarely a case where nitrogen fertilizer is not applied to a wheat field. The $R^{2}$ values of the previously best-performing index, MTVI2, varied between 0.491 and 0.786 , while those of ONLI ranged from 0.484 to 0.811 . Compared with MTVI2, the ONLI $R^{2}$ increased by $6.13 \%$ and the RMSE decreased by $9.07 \%$ across all datasets.

In order to understand the effects of different locations, cultivars, irrigation frequencies, planting density, $\mathrm{N}$ rates and years on the relationship between ONLI and LAI, the data from experiments 1-5 were used to carry out linear regression analysis. The horizontal cultivar 'Zhengmai 9694' and the intermediate cultivar 'Zhoumai 27' gave higher prediction accuracies (0.783 and 0.782), while the erect cultivar 'Yumai 49-198' gave an $R^{2}$ of only 0.707 (Fig. 8b). The $R^{2}$ values between ONLI and LAI varied with respect to irrigation level, with $R^{2}>0.78$ for W1 and W2, and an $R^{2}$ of 0.750 for W0 (Fig. 8c). For the plant density treatments, ONLI gave a high prediction accuracy $\left(R^{2}=0.753-0.787\right.$; Fig. $\left.8 \mathrm{~d}\right)$. Under different $\mathrm{N}$ treatments, the $R^{2}$ values of ONLI ranged from 0.484 to 0.733 , and increased with increasing $\mathrm{N}$ application rate (Fig. 8e). On the whole, except for the datasets in which the $\mathrm{N}$ rates were low $\left(<90 \mathrm{~kg} \mathrm{ha}^{-1}\right)$, the $R^{2}$ values of ONLI were all $>0.70$. Therefore, for all the datasets, the novel index ONLI is the most powerful vegetation index for estimating LAI.

Fig. 7 The unified relationship between LAI and the novel spectral index ONLI $(n=819)$

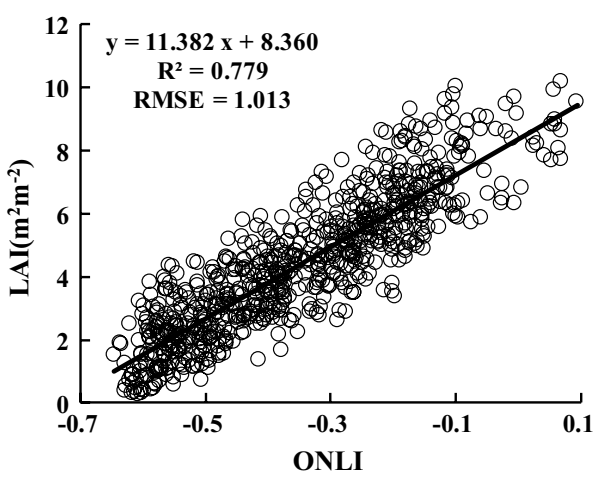




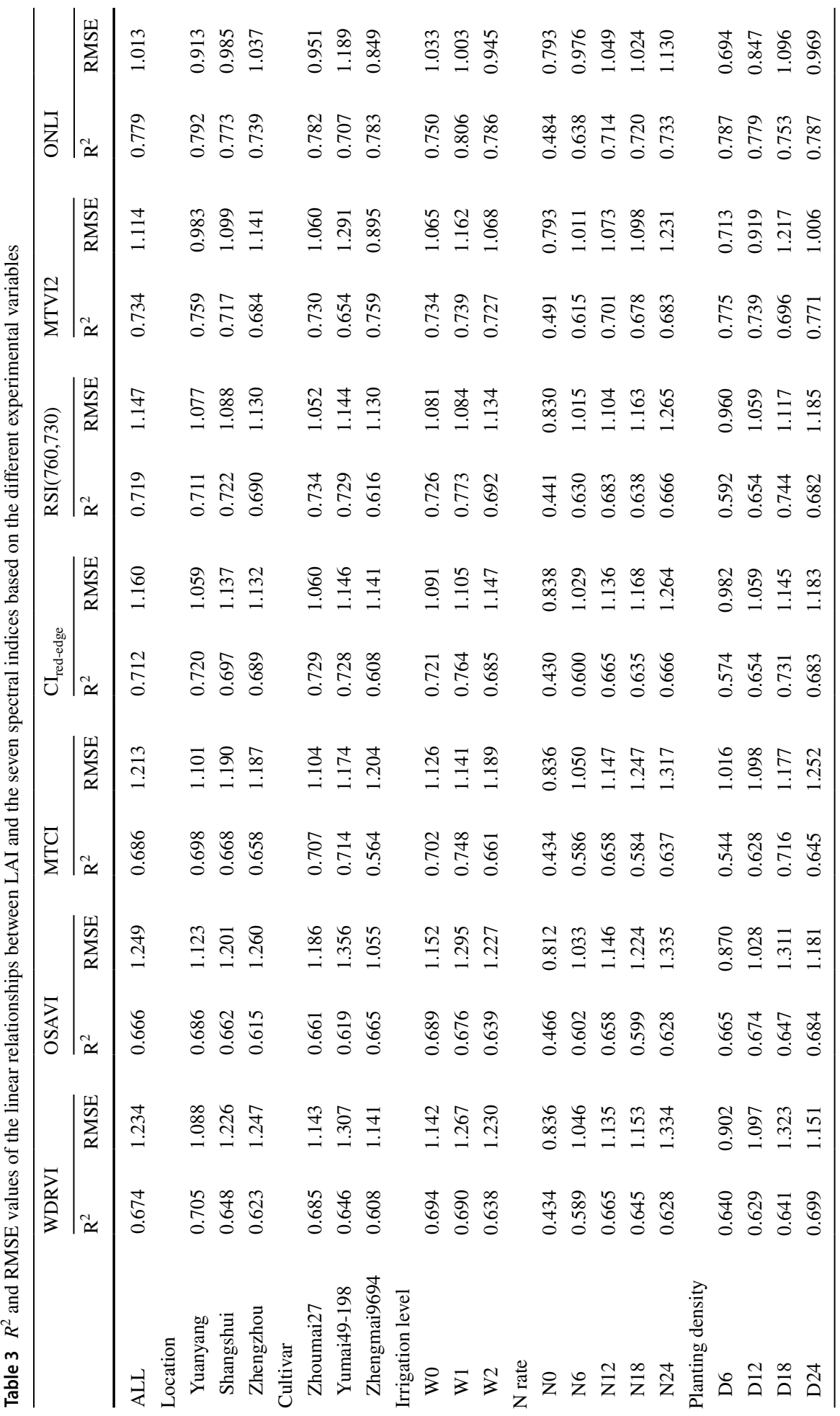




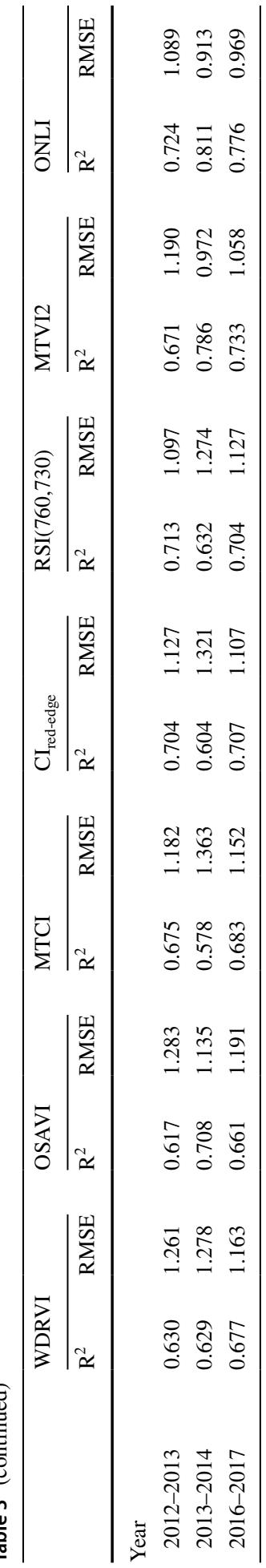



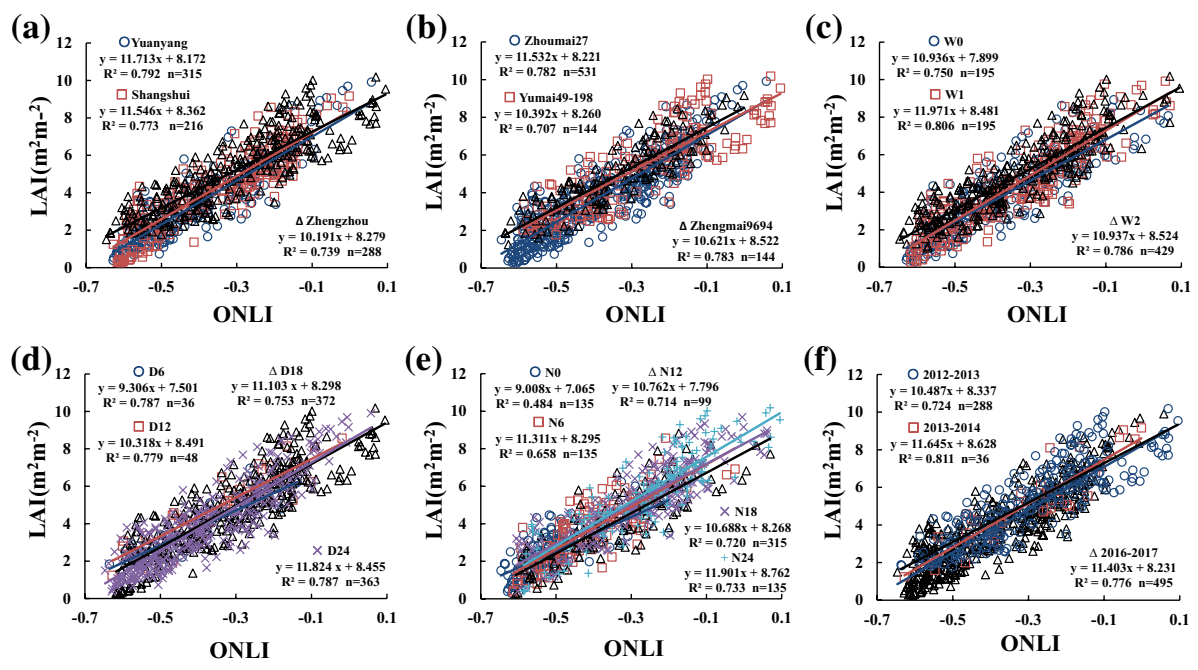

Fig. 8 Quantitative relationships between LAI and the novel spectral index ONLI under different field conditions $(n=819)$. The panels $\mathbf{a}-\mathbf{f}$ show analyses of separate datasets for location (a), cultivar (b), irrigation level (c), plant density (d), $\mathrm{N}$ rate $(\mathbf{e})$ and year $(\mathbf{f})$

\section{Discussion}

\section{Selection of sensitive bands}

Remote sensing is a very useful non-destructive tool for real-time monitoring of plant growth and physiological indices (Takebe et al. 1990). The narrowband spectral index has been reported to have greater sensitivity to $\mathrm{N}$ status and LAI (Hansen and Schjoerring 2003; Cao et al. 2017). Therefore, the selection of sensitive bands is very important in the construction of VIs. In order to improve the estimation of biochemical parameters, the sensitive bands of conventional VIs have undergone the development of red, green and blue bands; examples are the NDVI, green NDVI and $R_{434} /\left(R_{496}+R_{401}\right)$, among others (Rouse et al. 1974; Gitelson and Merzlyak 1997; Tian et al. 2011). However, the red-edge region ranging from 690 to $760 \mathrm{~nm}$ has a sharp change from the lowest absorption to the highest reflection (Horler et al. 1983), and is more sensitive than the visible bands to the LAI variability, canopy chlorophyll content and canopy structure (Filella et al. 1995; Herrmann et al. 2011; Hunt et al. 2013). Therefore, many red-edge indices (NDRE, $\mathrm{CI}_{\text {red-edge }}$ and MTCI) have been shown repeatedly to be able to provide good estimates of crop LAI (Peng et al. 2011; Viña et al. 2011; Gitelson et al. 2014; Tanaka et al. 2015). In this study, the VIs that include the red-edge band usually show better performance with respect to LAI estimation; for example, NDRE $\left(R^{2}=0.669\right)$ is better than NDVI $(810,680)\left(R^{2}=0.554\right)$ (Fig. 2). Compared with NLI $(810,680)$ and NLI $(868,550)$, NLI $(798,728)$ obtained by band optimization gave a higher fitting accuracy with LAI $\left(R^{2}=0.757\right.$; Fig. $\left.5 \mathrm{~b}\right)$, which also indicates that the red-edge band is more capable of detecting canopy depth under high biomass conditions (Ciganda et al. 2012). 


\section{Construction of new parameters by reducing the saturation effect}

It is well known that the relationships between most existing indices and the surface biophysical parameters are non-linear, such as the relationships of NDVI and OSAVI with LAI (Rouse et al. 1974; Rondeaux et al. 1996; Gitelson and Merzlyak 1997). This is because canopy reflectance is affected by many factors, and these influences interact with each other and are usually non-linear (Goel and Qin 1994). Therefore, in order to simulate the non-linear relationships between VIs and surface biophysical parameters, non-linear VIs emerged as the times require, such as NLI and RDVI (Goel and Qin 1994; Roujean and Breon 1995). In this study, compared with the widely used NDVI, the estimation precision of NLI and RDVI increased by $14.26 \%$ and $26.51 \%$, respectively (Fig. 2). NLI $(798,728)$ gave superior performance $\left(R^{2}=0.757\right)$ by taking full advantage of red edge and non-linearity, while the previous best-performing index, MTVI2, only gave an $R^{2}$ of 0.734 . The above non-linear VIs can linearize the relationships with LAI that to a great extent tend to be non-linear. Therefore, the non-linear VIs can reduce the saturation problem in LAI estimation and in turn improve the prediction accuracy.

The NDVI which consists of NIR and red, is the most well known and widely used VI (Rouse et al. 1974). However, the saturation of NDVI is a difficult problem that cannot be ignored and needs to be overcome. Reducing the reflectance contrast under conditions of high LAI is the key step to reducing the saturation (Gitelson 2004). The WDRVI enabled a better characterization of vegetation biophysical properties by introducing the weighting coefficient "a", which weakens the reflectance contrast under high LAI conditions and thus reduces the saturation (Gitelson 2004). The red-edge wide dynamic range vegetation index (red-edge WDRVI) retains the advantage of the coefficient "a" and weakens the saturation (Nguy-Robertson et al. 2014). The modified normalized difference spectral index (mNDSI) proposed by Cao et al. (2017) also uses this principle to add the coefficient " $k$ " to improve the sensitivity to LAI and reduce the saturation. In this research, when compared with NDVI, WDRVI increased its predictive ability by $21.65 \%$ by adding the weighting coefficient "a" (Fig. 2).

It is well known that canopy reflectance is easily affected by the optical properties of the soil background, such as soil brightness (Huete 1988; Rondeaux et al. 1996). The soil adjustment factor " $L$ " plays a role in minimizing soil brightness, and its value varies based on the density conditions, which produce vegetation isolines more independent of soil background (Huete 1988). For example, the "L" values of OSAVI, VI and MNLI are set to 0.16, 0.45 and 0.5, respectively (Rondeaux et al. 1996; Gong et al. 2003; Reyniers et al. 2006). In this study, OSAVI and MNLI both showed improved prediction accuracy ( $>13 \%$ ) compared with the initial NDVI and NLI by introducing the soil adjustment factor "L".

Inspired by these earlier successes, the authors further modified NLI $(798,728)$ by introducing both " $\mathrm{L}$ " and "a" to reduce soil effects and reflectance contrast. Through the co-operative optimization of the above two factors, "L" and "a" were set to 0.05 and 0.6, respectively. This optimized non-linear vegetation index (ONLI) takes the form of $(1+0.05) \times\left(0.6 \times R_{798}^{2}-R_{728}\right) /\left(0.6 \times R_{798}^{2}+R_{728}+0.05\right)$, and generates better predicting performance with $R^{2}=0.779$, an increase of $2.91 \%$ in $R^{2}$ and a decrease of $7.57 \%$ in RMSE compared with the former NLI $(798,728)$. Therefore, ONLI improved the estimation accuracy of LAI by the comprehensive contributions of the soil factor and weighting coefficient, and its prominent characteristic was a reduction in the saturation 
effect of LAI estimation, especially under conditions where LAI is high. This will provide a method for accurate estimation of higher LAI under sufficient water, fertilizer and planting density driven by the goal of super-high yield in agricultural production.

\section{Stability of the new index under different cultivation factors}

Crop production is influenced by many cultivation factors, hence it is necessary to seriously consider which factors may affect the accuracy of LAI estimation. In this study, for the $\mathrm{N}$ treatment, the ONLI $R^{2}$ values increased as the $\mathrm{N}$ application rate increased (Fig. 8e). This may be because LAI and plant $\mathrm{N}$ concentration are closely related to the $\mathrm{N}$ application rate in wheat (Plénet and Lemaire 2000; Chen et al. 2010), which resulted in a weakening of the effect of soil background on the canopy reflectance spectrum at high $\mathrm{N}$ application rates. Water is an all-important factor for crop growth. The $R^{2}$ values between ONLI and LAI showed differences in performance with $R^{2}>0.78$ for $\mathrm{W} 1$ and $\mathrm{W} 2$, and an $R^{2}$ of 0.750 for W0 (Fig. 8c). In this research, experimental fields are irrigated, and irrigation promotes wheat growth significantly. Less interference from soil factors resulted in the improved $R^{2}$ values for both $\mathrm{W} 1$ and $\mathrm{W} 2$.

The relative ability of ONLI to estimate LAI varied based on the different cultivar types (Fig. 8b), and this phenomenon may be due to inherent differences in leaf and canopy structures in the cultivars. Leaf direction can affect the canopy structure and light distribution, which in turn affects the canopy reflectance (Bertheloot et al. 2008). Different plant types lead to different crop coverage for the same planting density, which then has a large influence on the crop canopy spectrum. 'Zhengmai 9694' is a horizontal cultivar, and the relatively lesser effect of the soil factor led to a higher $R^{2}(0.783)$. 'Yumai 49-198' is an erect cultivar, and a larger contribution from the soil and more light leakage loss resulted in a lower estimation capability $\left(R^{2}=0.707\right)$. The estimation accuracies of ONLI were somewhat different for the different years and locations (Fig. 8a, f), which may be due to the unique environment resulting from meteorological conditions, soil types and residue background (Justes et al. 1994). This performance indicates that ONLI is unaffected by location and year, and can thus be applied under different locations and years.

Compared with the six selected common VIs, the ONLI $R^{2}$ values were the highest in nineteen out of the 21 groups (Table 3). Moreover, except for low $\mathrm{N}$ rates (below $90 \mathrm{~kg} \mathrm{ha}^{-1}$ ), the ONLI $R^{2}$ values were all $>0.70$ (Fig. 8). These results indicate that the novel index ONLI has strong adaptability to various conditions and can give good estimates of LAI for winter wheat across different field factors. On the whole, the variations in $R^{2}$ under various experimental conditions may be caused by the high degree of heterogeneity of the external environment. However, this difference is understandable and does not diminish the ability of the ONLI method to estimate the LAI of winter wheat with acceptable accuracy. Certainly, some other factors may affect the ability of the new index to accurately estimate LAI, which need to be further verified.

\section{Conclusion}

Remote sensing technology is a very important tool for the non-destructive, real-time monitoring of plant growth but the saturation of common VIs seriously limits the wide application of remote sensing technology to crop production management. The non-linear VIs were constructed to improve the relationship with LAI by reducing reflectance contrast. 
The authors optimized the band combinations and found that NLI $(798,728)$ demonstrated better predictive capability. Through the cooperative optimization of the soil factor and weighting coefficient, NLI $(798,728)$ was further modified. The novel index ONLI can be calculated by the formula: $(1+0.05) \times\left(0.6 \times R_{798}^{2}-R_{728}\right) /\left(0.6 \times R_{798}^{2}+R_{728}+0.05\right)$. The unified ONLI model was established to reduce saturation in the LAI estimation across different experimental conditions, and the predicted accuracy reached an $R^{2}$ of 0.779 . Therefore, this novel index proved to be an accurate predictor of LAI under different field factors, and could be used to guide field management in crop production.

Acknowledgements This work was supported by Grants from the Thirteenth Five-year Plan of National Key Research Project of China (2016YFD0300604), the National Natural Science Foundation of China (31671624), the Program of Science \& Technology Innovation Talents in Universities of Henan Province, China (17HASTIT036) and the Key Technologies R\&D Program of Henan Province, China (192102110118).

Author contributions WF and LH designed the research and conceptualized the manuscript. WF and YW wrote the manuscript. YW, XR, YW, and GH contributed tables and figures. YW, WL, and TG reviewed the manuscript and put forward suggestions for amendment.

\section{Compliance with ethical standards}

Conflict of interest The authors declare that they have no conflict of interest.

Open Access This article is distributed under the terms of the Creative Commons Attribution 4.0 International License (http://creativecommons.org/licenses/by/4.0/), which permits unrestricted use, distribution, and reproduction in any medium, provided you give appropriate credit to the original author(s) and the source, provide a link to the Creative Commons license, and indicate if changes were made.

\section{References}

Arias, D., Calvo-Alvarado, J., \& Dohrenbusch, A. (2007). Calibration of LAI-2000 to estimate leaf area index (LAI) and assessment of its relationship with stand productivity in six native and introduced tree species in Costa Rica. Forest Ecology and Management, 247(1-3), 185-193.

Baret, F., \& Guyot, G. (1991). Potentials and limits of vegetation indices for LAI and APAR assessment. Remote Sensing of Environment, 35(2-3), 161-173.

Bertheloot, J., Martre, P., \& Andrieu, B. (2008). Dynamics of light and nitrogen distribution during grain filling within wheat canopy. Plant Physiology, 148(3), 1707-1720.

Bréda, N. J. J. (2003). Ground-based measurements of leaf area index: a review of methods, instruments and current controversies. Journal of Experimental Botany, 54(392), 2403-2417.

Cao, Z. S., Cheng, T., Ma, X., Tian, Y. C., Zhu, Y., Yao, X., et al. (2017). A new three-band spectral index for mitigating the saturation in the estimation of leaf area index in wheat. International Journal of Remote Sensing, 38(13), 3865-3885.

Casas, A., Riaño, D., Ustin, S. L., Dennison, P., \& Salas, J. (2014). Estimation of water-related biochemical and biophysical vegetation properties using multitemporal airborne hyperspectral data and its comparison to MODIS spectral response. Remote Sensing of Environment, 148, 28-41.

Champagne, C. M., Staenz, K., Bannari, A., McNairn, H., \& Deguise, J. C. (2003). Validation of a hyperspectral curve-fitting model for the estimation of plant water content of agricultural canopies. Remote Sensing of Environment, 87(2-3), 148-160.

Chason, J. W., Baldocchi, D. D., \& Huston, M. A. (1991). A comparison of direct and indirect methods for estimating forest canopy leaf area. Agricultural and Forest Meteorology, 57(1-3), 107-128.

Chen, P. F., Haboudane, D., Tremblay, N., Wang, J. H., Vigneault, P., \& Li, B. G. (2010). New spectral indicator assessing the efficiency of crop nitrogen treatment in corn and wheat. Remote Sensing of Environment, 114, 1987-1997. 
Ciganda, V. S., Gitelson, A. A., \& Schepers, J. (2012). How deep does a remote sensor sense? Expression of chlorophyll content in a maize canopy. Remote Sensing of Environment, 126, 240-247.

Cutini, A., Matteucci, G., \& Mugnozza, G. S. (1998). Estimation of leaf area index with the Li-Cor LAI2000 in deciduous forests. Forest Ecology and Management, 105(1-3), 55-65.

Dash, J., \& Curran, P. J. (2004). The MERIS terrestrial chlorophyll index. International Journal of Remote Sensing, 25(23), 5403-5413.

Daughtry, C. S. T. (1990). Direct measurements of canopy structure. Remote Sensing Reviews, 5(1), 45-60.

Filella, I., Serrano, L., Serra, J., \& Peñuelas, J. (1995). Evaluating wheat nitrogen status with canopy reflectance indices and discriminant analysis. Crop Science, 35, 1400-1405.

Fitzgerald, G. J., Rodriguez, D., Christensen, L. K., Belford, R., Sadras, V. O., \& Clarke, T. R. (2006). Spectral and thermal sensing for nitrogen and water status in rainfed and irrigated wheat environments. Precision Agriculture, 7, 233-248.

Gitelson, A. A. (2004). Wide dynamic range vegetation index for remote quantification of biophysical characteristics of vegetation. Journal of Plant Physiology, 161, 165-173.

Gitelson, A. A., \& Merzlyak, M. N. (1994). Spectral reflectance changes associated with autumn senescence of Aesculus hippocastanum L. and Acer platanoides L. leaves: spectral features and relation to chlorophyll estimation. Journal of Plant Physiology, 143, 286-292.

Gitelson, A. A., \& Merzlyak, M. N. (1997). Remote estimation of chlorophyll content in higher plant leaves. International Journal of Remote Sensing, 18, 2691-2697.

Gitelson, A. A., Peng, Y., Arkebauer, T. J., \& Schepers, J. (2014). Relationships between gross primary production, green LAI, and canopy chlorophyll content in maize: Implications for remote sensing of primary production. Remote Sensing of Environment, 144, 65-72.

Gitelson, A. A., Vina, A., Ciganda, V., Rundquist, D. C., \& Arkebauer, T. J. (2005). Remote estimation of canopy chlorophyll content in crops. Geophysical Research Letters, 32, 1-4.

Goel, N. S., \& Qin, W. (1994). Influences of canopy architecture on relationships between various vegetation indices and LAI and FPAR: A computer simulation. Remote Sensing of Environment, 10, 309-347.

Gong, P., Pu, R. L., Biging, G. S., \& Larrieu, M. R. (2003). Estimation of forest leaf area index using vegetation indices derived from hyperion hyperspectral data. IEEE Transactions on Geoscience and Remote Sensing, 41, 1355-1362.

Haboudane, D., Miller, J. R., Pattey, E., Zarco-Tejada, P. J., \& Strachan, I. B. (2004). Hyperspectral vegetation indices and novel algorithms for predicting green LAI of crop canopies: Modeling and validation in the context of precision agriculture. Remote Sensing of Environment, 90, 337-352.

Hansen, P. M., \& Schjoerring, J. K. (2003). Reflectance measurement of canopy biomass and nitrogen status in wheat crops using normalized difference vegetation indices and partial least squares regression. Remote Sensing of Environment, 86, 542-553.

He, L., Zhang, H. Y., Zhang, Y. L., Song, X., Feng, W., Kang, G. Z., et al. (2016). Estimating canopy leaf nitrogen concentration in winter wheat based on multi-angular hyperspectral remote sensing. European Journal of Agronomy, 73, 170-185.

Heiskanen, J., Rautiainen, M., Stenberg, P., Mõttus, M., Vesanto, V. H., Korhonen, L., et al. (2012). Seasonal variation in MODIS LAI for a boreal forest area in Finland. Remote Sensing of Environment, 126, 104-115.

Herrmann, I., Pimstein, A., Karnieli, A., Cohen, Y., Alchanatis, V., \& Bonfil, D. J. (2011). LAI assessment of wheat and potato crops by Venus and Sentinel-2 bands. Remote Sensing of Environment, 115(8), 2141-2151.

Horler, D. N. H., Dockray, M., \& Barber, J. (1983). The red edge of plant leaf reflectance. International Journal of Remote Sensing, 4(2), 273-288.

Huete, A. R. (1988). A soil-adjusted vegetation index (SAVI). Remote Sensing of Environment, 25, 295-309.

Huete, A. R., Didan, K., Miura, T., Rodriguez, E. P., Gao, X., \& Ferreira, L. G. (2002). Overview of the radiometric and biophysical performance of the MODIS vegetation indices. Remote Sensing of Environment, 83(1-2), 195-213.

Hunt, E. R., Doraiswamy, P. C., McMurtrey, J. E., Daughtry, C. S. T., Perry, E. M., \& Akhmedov, B. (2013). A visible band index for remote sensing leaf chlorophyll content at the canopy scale. International Journal of Applied Earth Observation and Geoinformation, 21, 103-112.

Inoue, Y., Peñuelas, J., Miyata, A., \& Mano, M. (2008). Normalized difference spectral indices for estimating photosynthetic efficiency and capacity at a canopy scale derived from hyperspectral and $\mathrm{CO}_{2}$ flux measurements in rice. Remote Sensing of Environment, 112(1), 156-172.

Jiang, Z. Y., Huete, A. R., Didan, K., \& Miura, T. (2008). Development of a two-band enhanced vegetation index without a blue band. Remote Sensing of Environment, 112, 3833-3845. 
Justes, E., Mary, B., Meynard, J. M., Machet, J. M., \& Thelier-Huché, L. (1994). Determination of a critical nitrogen dilution curve for winter wheat crops. Annals of Botany, 74(4), 397-407.

Liang, L., Di, L. P., Zhang, L. P., Deng, M. X., Qin, Z. H., Zhao, S. H., et al. (2015). Estimation of crop LAI using hyperspectral vegetation indices and a hybrid inversion method. Remote Sensing of Environment, 165, 123-134.

Nguy-Robertson, A. L., Peng, Y., Gitelson, A. A., Arkebauer, T. J., Pimstein, A., Herrmann, I., et al. (2014). Estimating green LAI in four crops: Potential of determining optimal spectral bands for a universal algorithm. Agricultural and Forest Meteorology, 192-193, 140-148.

Peng, Y., Gitelson, A. A., Keydan, G., Rundquist, D. C., \& Moses, W. (2011). Remote estimation of gross primary production in maize and support for a new paradigm based on total crop chlorophyll content. Remote Sensing of Environment, 115, 978-989.

Plénet, D., \& Lemaire, G. (2000). Relationships between dynamics of nitrogen uptake and dry matter accumulation in maize crops. Determination of critical N concentration. Plant and Soil, 216, 65-82.

Qi, J., Chehbouni, A., Huete, A. R., Kerr, Y. H., \& Sorooshian, S. (1994). A modified soil adjusted vegetation index. Remote Sensing of Environment, 48, 119-126.

Reyniers, M., Walvoort, D. J. J., \& De Baardemaaker, J. (2006). A linear model to predict with a multispectral radiometer the amount of nitrogen in winter wheat. International Journal of Remote Sensing, 27(19), 4159-4179.

Rondeaux, G., Steven, M., \& Baret, F. (1996). Optimization of soil-adjusted vegetation indices. Remote Sensing of Environment, 55, 95-107.

Roujean, J. L., \& Breon, E. M. (1995). Estmating PAR absorbed by vegetation from bidirectional reflectance measurements. Remote Sensing of Environment, 51, 375-384.

Rouse, J.W., Haas, R.H., Schell, J.A., Deering, D.W., \& Harlan, J.C. (1974). Monitoring the vernal advancement and retrogradation (green wave effect) of natural vegetation. In: NASA/GSFC, Type III Final Report, Greenbelt, MD, USA, 371-373.

Takebe, M., Yoneyama, T., Inada, K., \& Murakami, T. (1990). Spectral reflectance ratio of rice canopy for estimating crop nitrogen status. Plant and Soil, 122, 295-297.

Tanaka, S., Kawamura, K., Maki, M., Muramoto, Y., Yoshida, K., \& Akiyama, T. (2015). Spectral index for quantifying leaf area index of winter wheat by field hyperspectral measurements: A case study in Gifu prefecture, central Japan. Remote Sensing, 7(5), 5329-5346.

Tian, Y. C., Yao, X., Yang, J., Cao, W. X., Hannaway, D. B., \& Zhu, Y. (2011). Assessing newly developed and published vegetation indices for estimating rice leaf nitrogen concentration with ground- and space-based hyperspectral reflectance. Field Crops Research, 120, 299-310.

Tillack, A., Clasen, A., Kleinschmit, B., \& Förster, M. (2014). Estimation of the seasonal leaf area index in an alluvial forest using high-resolution satellite-based vegetation indices. Remote Sensing of Environment, 141, 52-63.

Viña, A., Gitelson, A. A., Nguy-Robertson, A. L., \& Yi, P. (2011). Comparison of different vegetation indices for the remote assessment of green leaf area index of crops. Remote Sensing of Environment, 115, 3468-3478.

Wilson, J. W. (1960). Inclined point quadrats. New Phytologist, 59(1), 1-7.

Zarco-Tejada, P. J., Miller, J. R., Noland, T. L., Mohammed, G. H., \& Sampson, P. H. (2001). Scaling-up and model inversion methods with narrowband optical indices for chlorophyll content estimation in closed forest canopies with hyperspectral data. IEEE Transactions on Geoscience and Remote Sensing, 39(7), 1491-1507.

Publisher's Note Springer Nature remains neutral with regard to jurisdictional claims in published maps and institutional affiliations. 